\title{
Characterization of compacted silty sand via relative humidity-controlled triaxial testing
}

\author{
Ujwalkumar D. Patil ${ }^{1, a}$, Laureano R. Hoyos ${ }^{2}$, and Anand J. Puppala ${ }^{3}$ \\ ${ }^{1}$ Faculty Research Associate, University of Texas at Arlington, Arlington, Texas 76019, USA. \\ ${ }^{2}$ Professor, University of Texas at Arlington, Arlington, Texas 76019, USA. \\ ${ }^{3}$ Professor, University of Texas at Arlington, Arlington, Texas 76019, USA.
}

\begin{abstract}
Rather limited experimental evidence is available of triaxial shear-induced response of unsaturated soils at suction states far beyond residual suction. In this work, a fully automated, relative-humidity (Auto-RH) control unit is adapted to a newly implemented double-walled triaxial cell to test compacted silty sand specimens under considerably high total suction states via the vapor-pressure technique. The work is intended to gain critical insight into some of the most essential hydro-mechanical features of densely compacted intermediate geomaterials, such as post-peak softening and strain-induced dilatancy, under suction-controlled monotonic shearing. In general, peak strength is followed by large strain-induced softening until critical state is apparently reached. Strain-softening is observed to become considerably more pronounced with increasing total suction. The slope of critical state lines, however, remains virtually constant, regardless of induced total suction, in agreement with critical state-based constitutive frameworks previously postulated for unsaturated soils.
\end{abstract}

Key words: Unsaturated soils, vapor-pressure technique, double-wall triaxial cell, critical state line.

\section{Introduction}

Recently, researchers have shown growing interest in assessment of soil shear strength and stiffness behaviors in the high suction range ([8], [17], [2], and [9]). However, use of the axis-translation technique to impose high soil suction is limited (to about $1500 \mathrm{kPa}$ ) by the air-entry value of the ceramic disk. Changes in moisture content in unsaturated soil specimens at suction greater than approximately $3,000 \mathrm{kPa}$ can be controlled using vapor phase equilibrium [9]. This method has been used to measure triaxial shear strength and volume change behavior of a non-plastic silty soil at high suction range, under controlled relative humidity environment, by regulating the inflow rate of air ([11] and [10]).

Although, the oedometer and direct shear tests are comparatively simple to be conduct, the triaxial testing facilitates soil testing along a wide variety of stress paths, thereby simulating different field conditions encountered in the geotechnical practice [2]. A substantial portion of the data available on unsaturated soil behavior has been obtained using the axis-translation technique (i.e. low-tomedium suction range). However, research using osmotic or vapor pressure based techniques in the higher suction range (i.e. above residual suction range), is very limited. This study is one of the few attempts made on high suc- tion-based soil strength tests as it pertains to intermediate geomaterials.

An attempt has been made at Geomechanics laboratory of University of Texas at Arlington to develop a new apparatus by accommodating the RH triaxial equipment, in conjunction with the triaxial device, to directly control the relative humidity inside the specimen. Shear induced strength/volume change behavior in high total suction range is studied in current research. Same equipment was previously used to accommodate axis-translation technique to test soil specimen up to matric suction of 1500 $\mathrm{kPa}$ [13]. Present modifications have enhanced the capabilities of this triaxial equipment to test soil specimen up to total suction as high as $300 \mathrm{MPa}$. Efficacy of this equipment to reproduce similar test results at low, medium and high suction range has been performed and documented by [14].

\section{Test material}

The test soil comprised of $55 \%$ sand, $37 \%$ silt and $8 \%$ clay and is classified as silty sand (SM) according to the Unified Soil Classification system (USCS). Properties of compacted test soil specimen prepared by static compaction method are summarized in Table 1.

\footnotetext{
${ }^{\mathrm{a}}$ Corresponding author: ujwalkumar.patil@mavs.uta.edu
} 


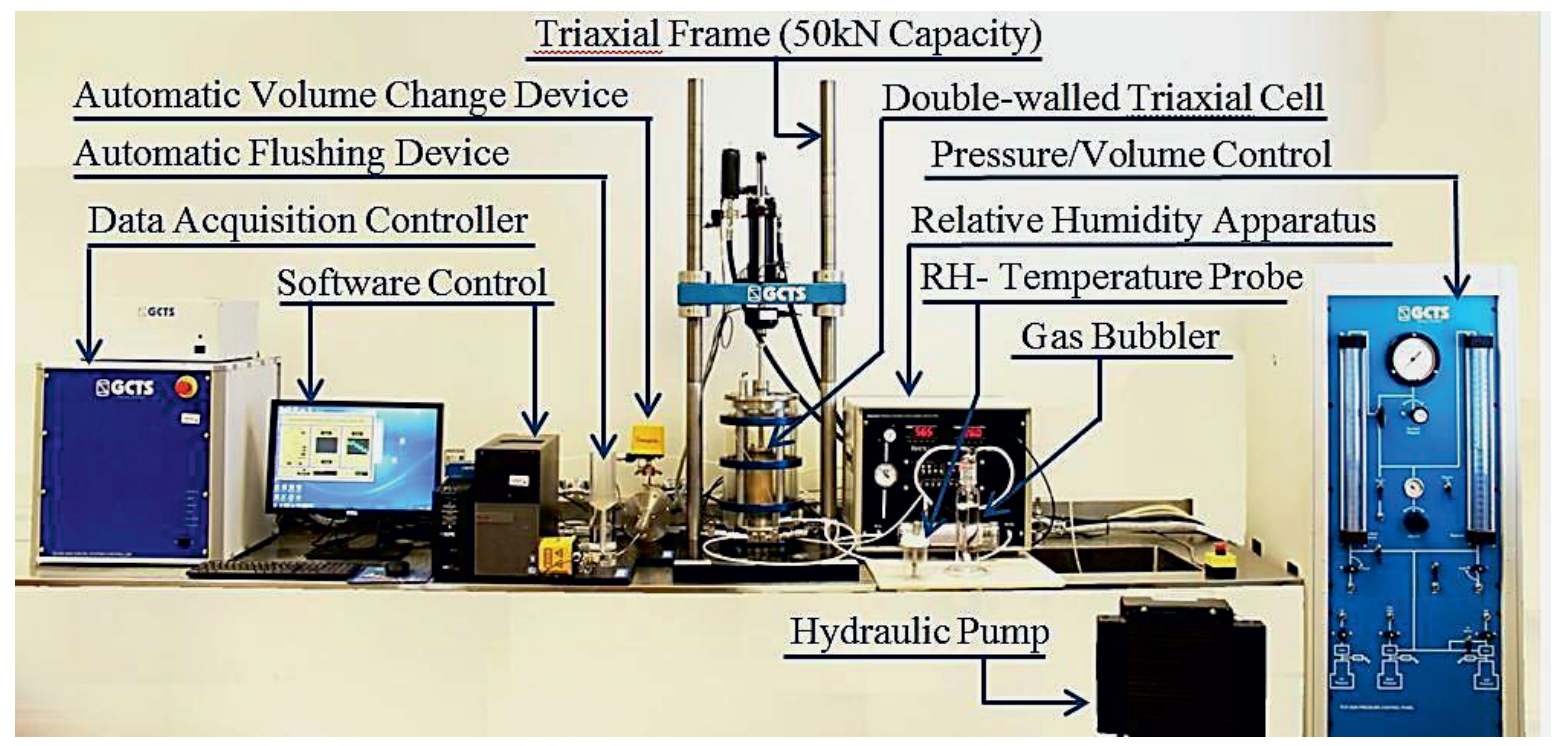

Figure 1. Panoramic view of entire Auto-RH/Triaxial test setup.

Table 1. As-compacted soil specimen properties.

\begin{tabular}{ll}
\hline Dry unit weight, $\rho_{\mathrm{d}}$ & $1.8 \mathrm{~g} / \mathrm{cm}^{3}$ \\
Moisture content, $\mathrm{w}$ & $14.2 \%$ \\
Air entry value $(\mathrm{AEV})$ & $10 \mathrm{kPa}$ \\
Initial voids ratio $\left(\mathrm{e}_{\text {initial }}\right)$ & $0.46-0.49$ \\
Diameter & $2.8 \mathrm{in}$ \\
Height & $5.6 \mathrm{in}$ \\
\hline
\end{tabular}

\section{Specimen preparation(s)}

Each specimen was statically compacted in nine equal layers. Each layer was compacted at a constant rate of 1 $\mathrm{mm} / \mathrm{min}$ to a total vertical stress of $1600 \mathrm{kPa}$ to produce overall homogenous specimen [14]. The convention used to designate the specimen is $\mathrm{CD}_{\mathrm{x}-\mathrm{y}}$ where "CD" denotes the consolidated drained test; " $x$ " represents the net confining pressure $\left(\sigma_{3}-u_{a}\right)$, while " $y$ " represents the imposed constant matric suction $\left(\mathrm{u}_{\mathrm{a}}-\mathrm{u}_{\mathrm{w}}\right)$.

\section{Auto-RH triaxial setup}

The Auto-RH system [6] and [7], designed is capable of automatic control of relative humidity $(\mathrm{RH})$ between $1 \% \mathrm{RH}$ and $\sim 99 \% \mathrm{RH}$. This corresponds to a total suction range of $600 \mathrm{MPa}$ to $1.4 \mathrm{MPa}$. The thermodynamic relationship between relative humidity of pore water vapor and total suction $\Psi_{t}(\mathrm{kPa})$ is given by Kelvin's equation (1):

$\psi_{t}=-\frac{R T}{v_{w o} \omega_{v}} \ln \left(\frac{u_{v}}{u_{v o}}\right)=-\frac{R T}{v_{w o} \omega_{v}} \ln (\mathrm{RH})$

where $u_{v}$ is partial pressure of water (e.g., soil pore-water) vapor $(\mathrm{kPa}) ; u_{v o}=$ saturation pressure of pure water vapor $(\mathrm{kPa}) ; R=$ universal gas constant $\left(8.31432 \mathrm{~J} \mathrm{~mol}^{-1} \mathrm{~K}^{-1}\right) ; T$ $=$ absolute temperature $(K) ; v_{w o}=$ specific volume of water (reciprocal of density, $\mathrm{m}^{3} / \mathrm{kg}$ ); and, $\omega_{v}=$ molecular mass of water vapor $(18.016 \mathrm{~kg} / \mathrm{kmol})$.

Main features of the fully integrated system, also referred to as the Auto- $\mathrm{RH} /$ Triaxial system in this work, include: (1) Auto-RH control unit; (2) Gas bubbler, desiccant, and temperature probe; (3) Double-walled triaxial cell; (4) Automated volume-change device; and (5) Automated flushing device. Figure 1 shows a panoramic view of entire RH-Triaxial setup.

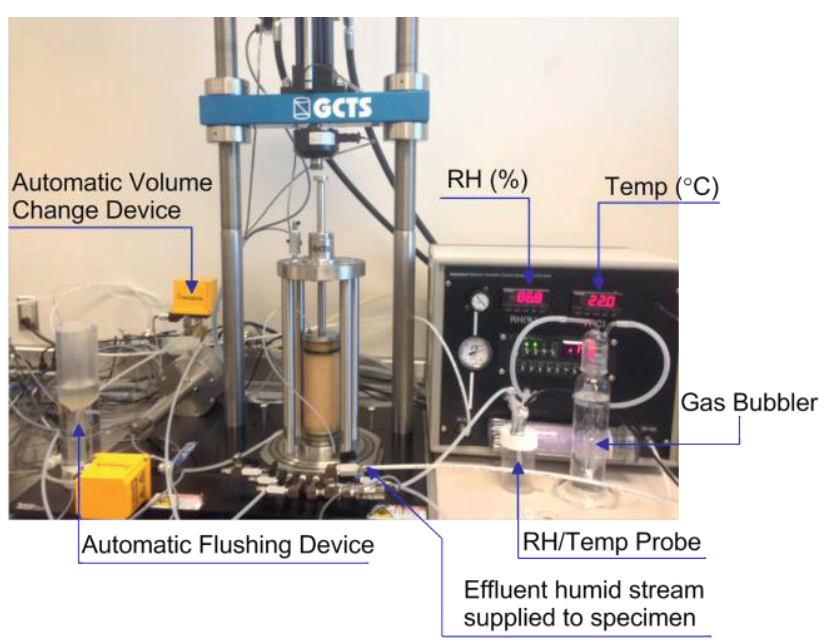

Figure 2. Triaxial setup with adapted Auto-RH control unit.

The double-walled chamber includes an inner cell subjected to same internal and external pressures, thus avoiding differential pressures and hence minimizing cell expansion and/or water leakage. The pressure and flow of water into the inner cell is controlled by a pressure and volume controller. The total change in volume experienced by the soil is equivalent to the amount of water flowing from (or into) the inner cell and into (or from) the outer cell. The total soil volume change was monitored by a volume-change device with a rolling diaphragm to minimize the sliding friction that normally occurs in conventional volume-change devices [14]. 
Humidity in the pore-air phase of the test soil can be ramped along paths of increasing or decreasing relative humidity, ranging from $\sim 2 \% \mathrm{RH}$ to $\sim 95 \% \mathrm{RH}$, which corresponds to total suction states of $\sim 500,000 \mathrm{kPa}(500$ $\mathrm{MPa})$ to $\sim 10,000 \mathrm{kPa}(10 \mathrm{MPa})$; and is typically accomplished in step increments of $\sim 10 \% \mathrm{RH}$. The "forcedflow" nature of the mixed-flow system significantly reduces the required pore-fluid equalization time [7].

\section{Test procedure}

\subsection{Suction equalization}

Statically compacted specimens prepared for triaxial testing were first air-dried under laboratory environment $\left(24^{\circ} \mathrm{C}\right)$ until the monitored water content came reasonably close to that corresponding to the desired total suction state, a process that took between 4-5 days. The specimen was then transferred to the calibration chamber connected to RH-apparatus for preconditioning of the pore-fluids prior to triaxial testing. The $\mathrm{RH}$ was incrementally stepped up/down to a desired value by proportioning the "wet" to "dry" gas flows, under constant feedback from the RH/Temp probe. It took between 8-10 days for the desiccated specimens to attain equilibrium (pore-fluid equalization under constant soil mass), irrespective of the magnitude of the total suction to be induced (20-300 $\mathrm{MPa})$.

The preconditioned specimen was then immediately mounted onto the bottom pedestal of the cell and O-ringsealed with a latex membrane. Target total suction states in triaxial specimens, were automatically attained by supplying vapor-saturated air from the Auto-RH unit into the specimen through bottom pedestal via $1 / 4$ in nylon tubing. The mounted specimen was finally allowed to equilibrate under target RH value for at least 15 additional days [14].

\subsection{Isotropic consolidation}

Upon reaching equilibrium, the triaxial double-walled cell was assembled and filled with water under a water pressure of $10 \mathrm{kPa}$. The $\mathrm{RH} / \mathrm{Temp}$ and the related total suction was continuously monitored from the suction equalization stage till shearing. This monitoring provided an indirect knowledge of total suction inside specimen. Volume changes experienced by the soil throughout testing stages were recorded via an automatic volume-change device, which allowed for accurate dimensions of the specimens to be accounted for prior to initiating each stage.

The next stage consisted of isotropic consolidation under controlled suction. This was done by increasing the cell pressure at the rate of $5 \mathrm{kPa} / \mathrm{hr}$., while keeping the circulation of relative humidity from bottom to top of the specimen. It should be noted that the bottom of the specimen was connected to the RH equipment; hence, no water back pressure was applied. The top of specimen was connected to the chamber with a RH probe that had a vent open to the atmosphere for the effluent (Fig. 2). Thus, the air pressure in the specimen was at atmospheric pressure (or reference zero). Depending upon the final consolidation pressure, $\left(\sigma_{3}-\mathrm{u}_{\mathrm{a}}\right)=100,200$, or $300 \mathrm{kPa}$, the application of desired isotropic consolidation pressure took 18, 38, and 58 hrs, respectively. Each specimen was kept for at least 24 hours after the consolidation pressure was applied to ensure complete dissipation of pore air pressure (no change in volume of specimen).

\subsection{Shearing under constant suction}

Once the isotropic consolidation process was complete, the total suction inside the specimen and the net confining pressure, $\left(\sigma_{3}-u_{a}\right)=100,200$, or $300 \mathrm{kPa}$, was kept constant and the specimen was sheared at a constant shearing rate of $0.0009 \% / \mathrm{min}$. Independent studies were conducted to determine appropriate shearing rate of $0.0009 \% / \mathrm{min}$ [12].

\section{Shear-induced soil response}

The newly developed Auto-RH equipment was used to conduct a series of consolidated-drained CTC tests on nine identically prepared specimens of compacted SM soil under either saturated $(\mathrm{s}=0)$ or constant total suction states of $20 \mathrm{MPa}$ or $300 \mathrm{MPa}$. Specimens were sheared under initial net confining pressures of 100,200 , or 300 $\mathrm{kPa}$. Figure $3 \mathrm{a}$ and $3 \mathrm{~b}$ show the stress-strain and volumechange response of compacted SM soil from suctioncontrolled CTC tests conducted at initial net confinement, $\left(\sigma_{3}-\mathrm{u}_{\mathrm{a}}\right)=100 \mathrm{kPa}$. Similar tests were conducted at initial net confinement, $\left(\sigma_{3}-\mathrm{u}_{\mathrm{a}}\right)=200 \mathrm{kPa}$ and $300 \mathrm{kPa}$ with total suction, $\mathrm{s}=0,20$, and $300 \mathrm{MPa}$.

Fig 3a clearly indicates an increase in soil stiffness (tangent modulus), peak strength, and soil brittleness with increasing total suction. In general, peak strength is followed by large strain-induced softening, until critical state is apparently reached. Thereby strain-hardening type response, observed in saturated specimens, progressed towards strain-softening type response with the introduction of higher soil suction. This strain-softening, in turn, is observed to become considerably more pronounced with increasing total suction: The specimens failed at lower strains under highest total suction of 300 $\mathrm{MPa}$, then featuring a sudden drop in deviator stress, until eventually reaching critical state with a relatively small change in strain.

Figure $3 b$ clearly manifests the change in shearinduced volumetric response from initial compressive to dilational type when the soil saturation state changed from saturated to unsaturated state with the introduction of total suction of magnitude 20 and $300 \mathrm{MPa}$.

All the specimens showed initial compression, followed by a stress-induced dilatancy-type response that increased with an increase in the suction induced. Such types of stress-strain and volumetric response are typical of dense or overconsolidated soils. All the specimens showed brittle type failure, without any bulging (Fig. 4b). Similar observations were made from testing SM soil at net confining pressure, $\left(\sigma_{3}-u_{a}\right)=200 \mathrm{kPa}$ [14]. Figure 4a shows the homogenous compacted specimen with no visible cracks prior to testing while Figure $4 \mathrm{~b}$ shows failed specimen at the end of test. 

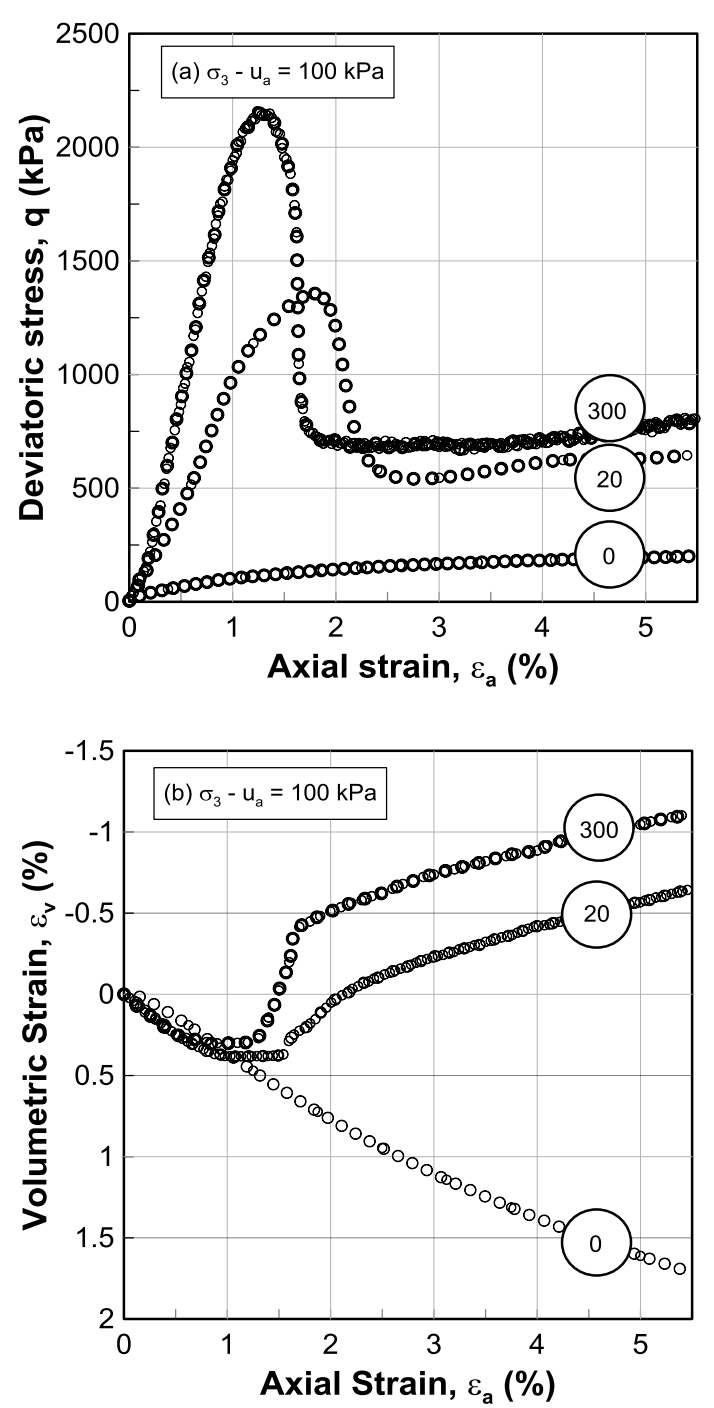

Figure 3. Response of compacted silty sand at net confining pressure, $\left(\sigma_{3}-u_{a}\right)=100 \mathrm{kPa}$, and total suctions of 0,20 , and 300 $\mathrm{MPa}$ : (a) stress-strain response, (b) volume change. (a)

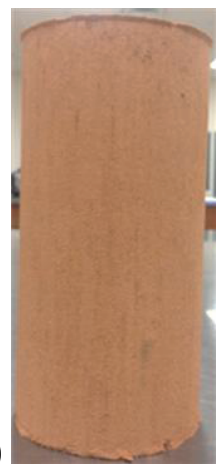

(b)

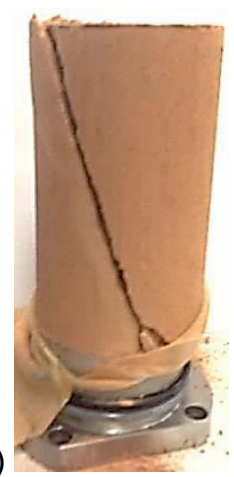

Figure 4. Typical features of as-compacted and failed silty sand specimens: (a) Desiccated specimen before testing, (b) Brittle type failure after CDRH300-300MPa triaxial test.

On the other hand, a considerable increase in net confining pressure, from 100 to $300 \mathrm{kPa}$, appears to have inhibited the relatively large amount of shear-induced dilation that is expected from SM soil when tested under higher total suction (300 MPa).

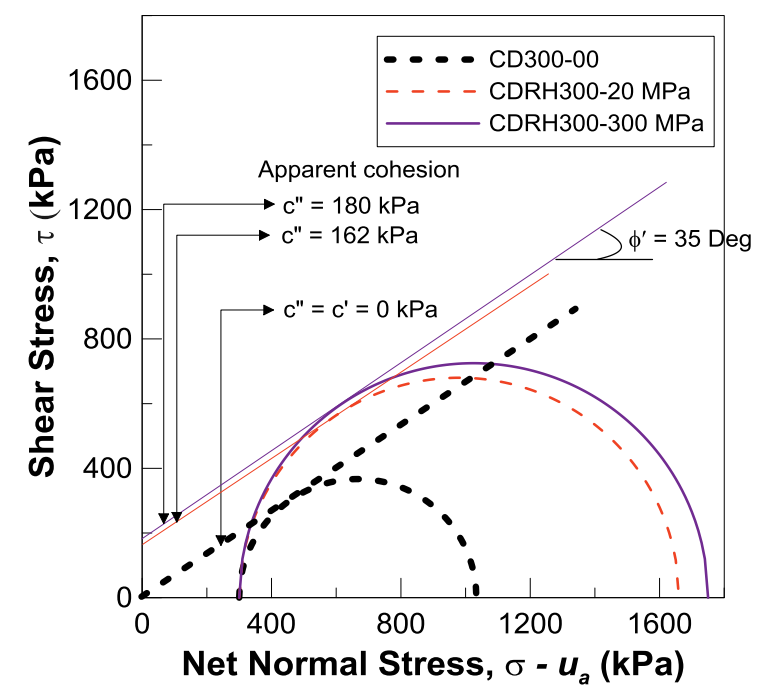

Figure 5. Mohr circles at critical state condition under net confining pressure, $\left(\sigma_{3}-\mathrm{u}_{\mathrm{a}}\right)=300 \mathrm{kPa}$, and total suctions of 0,20 , and $300 \mathrm{MPa}$.

This can be attributed to large particle crushing under such high net confinements, which yields a particle gradation that renders a soil less dilational in nature. These observations substantiate some of the key findings reported from previous works on similar types of intermediate geomaterials [3] and [18].

Figure 5 shows Mohr's stress circles drawn at critical state failure. The angle of internal friction $\varphi^{\prime}=35 \mathrm{deg}$. remains unchanged with increase in total suction up to $300 \mathrm{MPa}$. In fact, the failure envelope obtained at $\mathrm{s}=300$ $\mathrm{MPa}$ appeared to be very similar to that obtained by [5]. Clearly, there is no effect of change in soil suction on angle of internal friction. Figure 6 manifests an upward shift in critical state lines (CSL) with increase in soil suction. It also illustrates that slope of CSL is independent of increase in suction inside the specimen.

\section{Effect of suction on critical state lines}

Figures 6 shows the best-fit critical state lines (CSLs) obtained from triaxial testing at soil suction $\mathrm{s}=0,20$ and $300 \mathrm{MPa}$ via vapor-pressure technique. The critical state line is shifted upward with an increase in total suction, thereby, causing an increase in suction stress. The slope of all critical state lines, however, remains virtually constant, in close agreement with the constitutive, critical state based framework postulated by [1] and similar to [15 and 16].

\section{Concluding remarks}

A newly developed Auto-RH/Triaxial system was used to conduct Consolidated-drained CTC tests on specimens of compacted SM soil under total suctions of 0-300 MPa. In general, shear strength at peak and critical state increased with increasing total suction. Peak strength is followed by large strain-induced softening, until critical state is apparently reached. Strain-softening is also observed to be considerably more pronounced with increasing suction. 


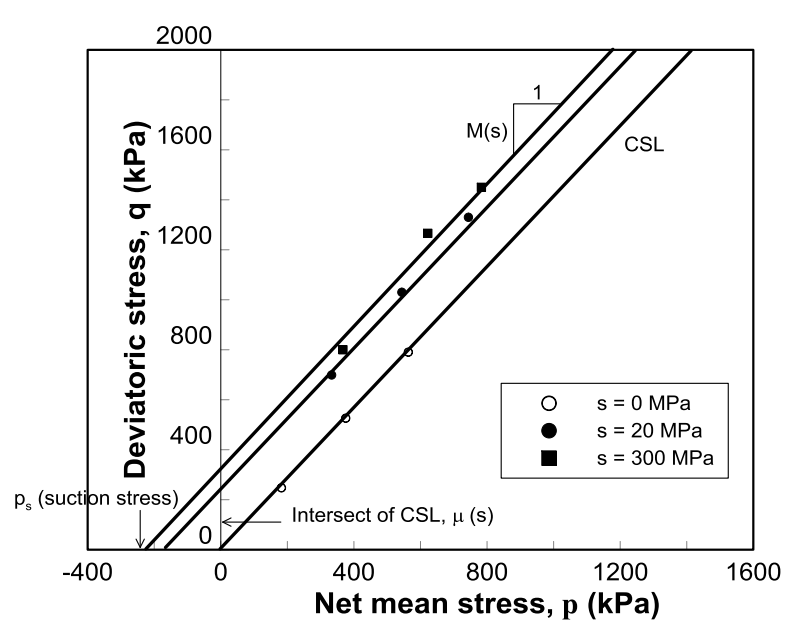

Figure 6. Critical state lines (CSLs) under net confining pressures, $\left(\sigma_{3}-u_{a}\right)=100,200$, and $300 \mathrm{kPa}$, and total suctions of 0 , 20, and $300 \mathrm{MPa}$.

Test results clearly showed a marked change in shearinduced volumetric response from initially compressive to purely dilational type when total suction was increased from 0 (saturated) to 20 or $300 \mathrm{MPa}$. An increase in net confinement from $100 \mathrm{kPa}$ to $300 \mathrm{kPa}$ tends to inhibit the shear-induced dilation of SM soil under constant total suction. The slope of all critical state lines (CSLs) obtained via vapor-pressure technique remains virtually constant, in close agreement with the constitutive, critical state based framework originally postulated by [1].

Experimental results such as the one obtained by testing densely compacted geomaterials at low, medium and high suction will help in the calibration, verification and fine-tuning of constitutive models. Modeling such shearinduced continuous stress-strain response along entire suction range ( 0 to $300 \mathrm{MPa}$ ) is currently being studied at The University of Texas at Arlington.

\section{Acknowledgements}

The experimental work described in this paper is part of an ongoing research project funded by National Science Foundation (NSF-MRI award ID \# 1039956). This support is gratefully acknowledged. Any findings, conclusions, or recommendations expressed in this material are those of the authors and do not necessarily reflect the views of the National Science Foundation.

\section{References}

1. Alonso, E.E., Gens, A., and Josa, A. A constitutive model for partially saturated soils. Géotechnique, 40(3), 405-530, (1990).

2. Blatz, J. A., Graham, J., and Chandler, N. A. "Influence of suction on the strength and stiffness of compacted sand-bentonite." Canadian Geotechnical Journal, 39, 1005-1015, (2002).

3. Estabragh, A. R., Javadi, A. A., and Boot, J. C. "Effect of compaction pressure on consolidation behavior of unsaturated silty soil." Canadian Geotechnical Journal, 41(3), 540-550, (2004).
4. Hoyos, L. R., Diego D. Perez-Ruiz and Puppala, A.J. Modeling unsaturated soil response under suctioncontrolled true triaxial stress paths. International Journal of Geomechanics, ASCE. 12 (3), 292-308, (2012).

5. Jotisankasa, A., Coop, M., and Ridley, A. "The mechanical behaviour of an unsaturated compacted silty clay." Géotechnique, 59(5), 415-428, (2009).

6. Likos, W. J. "User Manual automated relative humidity control system," (2012).

7. Likos, W. J. and Lu, N. "Automated humidity system for measuring total suction characteristics of clay." Geotechnical Testing Journal, ASTM, (2), 1-12, (2003).

8. Mahalinga-Iyer, U. and Williams, D. J. "Unsaturated strength behavior of compacted lateritic soils." Géotechnique, 45(2), 317-320, (1985).

9. Nishimura, T., Toyota, H., Vanapalli, S. K. and Won, O. T. "Determination of the shear strength behavior of an unsaturated soil in the high suction range using vapor pressure technique." Proc. of the Ist European Conference on Unsaturated Soils. Unsaturated Soils: Advances in Geo-Engineering, Toll et al. (eds) CRC Press: Taylor and Francis Group, 441-447, (2008).

10. Nishimura, T. and Vanapalli, S. K. "Volume change and shear strength behavior of an unsaturated soil with high soil suction." 16th International Conference on Soil Mechanics and Geotechnical Engineering, 563-566, (2005).

11. Nishimura, T. and Fredlund, D. G. "A new triaxial apparatus for high total suction using relative humidity control." $12^{\text {th }}$ Asian Regional Conference on Soil Mechanics and Geotechnical Engineering, Leung et al. (eds), World Scientific Publishing, (2003).

12. Patil, U. D., Hoyos, L. R., and Puppala, A. J. "Suitable shearing rate for triaxial testing of intermediate soils under vapor controlled medium to high suction range." IFCEE 2015, ASCE, 2141-2150, (2015).

13. Patil, U. D., Puppala, A. J., and Hoyos, L. R. “Assessment of suitable loading rate for suctioncontrolled triaxial testing on compacted silty sand via axis-translation technique." Geo-Congress 2014, GSP 234, ASCE, 1307-1316, (2014).

14. Patil, U. D. "Response of unsaturated silty sand over a wider range of suction states using a novel doublewalled triaxial testing system." Ph.D. dissertation, Univ. of Texas at Arlington, Arlington, TX, (2014).

15. Toll, D.G., and Ong, B.H. "Critical state parameters for an unsaturated residual sandy clay." Géotechnique, 53(1), 93-103, (2003).

16. Toll, D.G."A framework for unsaturated soil behaviour." Géotechnique, 40(1), 31-44, (1990).

17. Vanapalli, S. K., and Fredlund, D. G. Comparison of different procedures to predict unsaturated soil shear strength." Advances in Unsaturated Geotechnics, 195 209, (2000).

18. Zhang, X., and Li, L. "Limitations in the constitutive modeling of unsaturated soils and solutions." Int. J. Geomech., 11(3), 174-185, (2011). 